Check for updates

Cite this: RSC Adv., 2017, 7, 30385

Received 14th May 2017

Accepted 8th June 2017

DOI: $10.1039 / c 7 r a 05455 f$

rsc.li/rsc-advances

\section{Wood adhesive application of poly(hydroxyurethane)s synthesized with a dimethyl succinate-based amide backbone $\uparrow$}

\author{
M. Tryznowski, (D) *a A. Świderska, ${ }^{\text {a }}$ T. Gołofit (D) a and Z. Żołek-Tryznowskab
}

Non-isocyanate poly(hydroxyurethane)s (PHUs) made by reacting bis(cyclic carbonate)s and amines are important alternatives to conventional polyurethanes. In this work, a series of PHUs was synthesized using a solvent-free, catalyst-free method from bis(2,3-dihydroxypropyl)ether dicarbonate and 1,3diaminopropane using differing molar ratios of dimethyl succinate to change selected properties of each $\mathrm{PHU}$. The obtained PHUs were characterized by FT-IR, ${ }^{1} \mathrm{H}$ NMR and ${ }^{13} \mathrm{C}$ NMR spectroscopy and their thermal properties and viscosities were determined. We report the use of the obtained PHUs as wood adhesives and the work of adhesion data determined using Owens-Wendt method. The mechanical properties (strength) of different PHU-wood joints were compared. It was found that the addition of dimethyl succinate increases the hydrophobicity of coatings by increasing the water contact angle and decreasing the polar component of the surface free energy of the PHU coatings. PHUs with urethane and amide backbones were stronger than those without.

\section{Introduction}

Non-isocyanate poly(hydroxyurethane)s (PHUs) are more environmentally friendly alternatives to conventional polyurethanes (PUs), which are produced using carcinogenic and mutagenic isocyanates ${ }^{1-5}$ such as, methylene diphenyl 4,4'-diisocyanate (MDI) and toluene diisocyanate (TDI). Furthermore, MDI and TDI are widely used in PU synthesis and both are classified under REACH - a European Union regulation. PUs are widely used in a number of industrial applications, including coatings, foams, paints, thermoplastics, adhesives and sealants. ${ }^{6-10}$ However, isocyanates, which are used to synthesize PUs, are considered to be hazardous to the environment and to human health. Hence, the chemistry of PHUs and their potential industrial applications have received increased attention in recent years.

There are various ways to make PHUs. The reaction between cyclic carbonates and polyfunctional amines is the most promising method of obtaining these polymers. ${ }^{11-18}$ The advantages of this synthesis over others are that contaminants are eliminated, toxic compounds are not used and carbon dioxide emissions are lower. In contrast to isocyanates, straight derivatives of cyclic carbonates such as, ethylene and propylene carbonate are non-toxic and biodegradable. In addition, they

${ }^{a}$ Warsaw University of Technology, Faculty of Chemistry, Noakowskiego 3, 00-664, Warsaw, Poland. E-mail: tryznowski@ch.pw.edu.pl

${ }^{b}$ Warsaw University of Technology, Faculty of Production Engineering, Narbutta 85, 00664, Warsaw, Poland

$\dagger$ Electronic supplementary information (ESI) available. See DOI: 10.1039/c7ra05455f are characterized by their resistance to water, so no unwanted foaming occurs during synthesis. Using cyclic carbonates and polyfunctional amines is a progressive and competitive way to produce PHUs on an industrial scale. ${ }^{10}$

PHUs are characterized by the presence of primary and secondary hydroxyl groups in the macromolecule, which allows to create intra- and intermolecular hydrogen bonding. This results in an increase in mechanical and chemical strength. ${ }^{19}$ However, PHUs show reduced sensitivity to moisture and organic solvents due to the presence of these hydroxyl groups. In previous work, we have shown that the use of PHUs is limited by their hydrophilic properties. ${ }^{20} \mathrm{PHU}$ coatings obtained from bis(2,3-dihydroxypropyl)ether dicarbonate and various aliphatic amines absorb water, so they should not be used in high humidity atmospheres.

Most studies of PHUs have been limited to their synthesis, characterization by spectroscopy validation and their thermal properties. Apart from a few reports, there is a lack of information about using PHUs as adhesives or coatings. ${ }^{20-24}$ Cornille et al. elaborated on PHUs by investigating the step growth polymerization of cyclic carbonates derived from commercial epoxy compounds and commercial diamines. ${ }^{21}$ These PHUs, which were used as adhesives in wood joints, exhibited greater strength than conventional PUs. ${ }^{21}$ Leitsch et al. synthesized a PHU/PU hybrid material with enhanced mechanical properties that were similar to those of typical PU adhesives. ${ }^{22}$ Zhang et al. presented a series of poly(amide-hydroxyurethane)s with elevated tensile strength properties. ${ }^{23}$ 


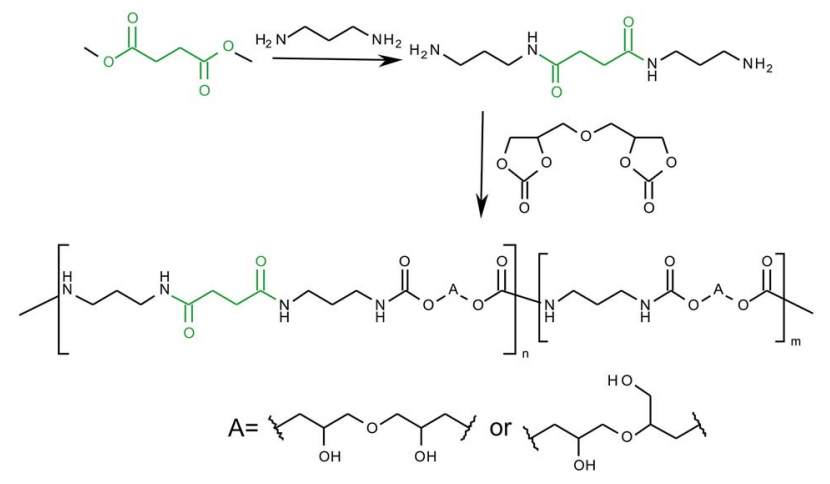

Scheme 1 Synthetic strategy for PHUs with urethane and amide backbones.

Nanclares et al. presented novel segmented polyurethanes synthesized via a non-isocyanate route and characterized by a relatively high tensile strength. ${ }^{24}$

The literature describes hybrid materials of PHU and conventional PU that modify the properties of $\mathrm{PHU},{ }^{22}$ but the synthesis requires the use of harmful isocyanates. In this work, the modification of PHU coatings using biodegradable esters is shown. In our opinion, the incorporation of an amide backbone should decrease the coatings' affinity to water, so PHU coatings will be able to be used in applications where they are exposed to high humidity. The high hydrophilicity of PHU compounds, due to the pendant hydroxyl groups, greatly limits their use in large-scale applications. Because of the great potential of PHU compounds - their environmentally friendly synthesis and mechanical properties - researchers should focus on chemical modifications to increase their hydrophobicity.

We present new types of PHUs containing both urethane and amide backbones. The PHUs were derived from bis(2,3dihydroxypropyl)ether dicarbonate and 1,3-diaminopropane. To improve the properties of the PHUs, dimethyl succinate was added in various molar ratios. As shown in Scheme 1, we propose an innovative synthetic route to PHUs with a urethane and an amide backbone. The spectral, thermal and rheological properties of the obtained polymers are presented. Moreover, a new potential application of obtained PHUs as a wood adhesive is presented.

\section{Experimental}

\subsection{Materials}

Dimethyl succinate (purity $\geq 99 \%$, CAS no. 106-65-0) and 1,3diaminopropane (purity $\geq 99 \%$, CAS no. 109-76-2) were purchased from Sigma-Aldrich (Poznan, Poland) and used as received.

Bis(2,3-dihydroxypropyl)ether dicarbonate was synthesized from a commercially available diglycerol as described in previous work. ${ }^{25}$

To perform contact angle measurements, diiodomethane was used as a dispersive liquid (purity 99\%, CAS no. 75-11-6, Sigma-Aldrich), while distilled water was used as a polar liquid.

\subsection{Instrumentation}

FT-IR spectra were recorded on a Bruker ALPHA FT-IR spectrometer equipped with a Platinum ATR single reflection diamond ATR module. The FT-IR measurements were carried out in the $400-4000 \mathrm{~cm}^{-1}$ wavelength range with a resolution of $4 \mathrm{~cm}^{-1}$.

${ }^{1} \mathrm{H}$ NMR and ${ }^{13} \mathrm{C}$ NMR spectra were recorded on a Varian VXR $400 \mathrm{MHz}$ spectrometer using tetramethylsilane as an internal standard and deuterated solvents $\left(\mathrm{CDCl}_{3}, \mathrm{DMSO}-\mathrm{d}_{6}\right)$ and analysed using MestReNova v.6.2.0e7238 (Mestrelab Research S.L.) software.

Calorimetric studies of the obtained PHUs were carried out using differential scanning calorimetry (DSC) on TA Instruments Q2000 apparatus and thermogravimetric analysis (TGA) was carried out on TA Instruments SDT Q600 apparatus, employing a heating rate (in both cases) of $10 \mathrm{~K} \mathrm{~min}^{-1}$.

Polymer viscosity measurements were performed on a Malvern Kinexus Pro rheometer (Malvern, England) using a parallel plate geometry (gap $0.4 \mathrm{~mm}$, spindle diameter $10 \mathrm{~mm}$ ). A standard mass of the sample $(0.3 \mathrm{~g})$ was placed symmetrically in the centre of the plate. The shear stress was measured at a constant shear rate, $\gamma=4 \mathrm{~s}^{-1}$ in $2 \mathrm{~min}$. The measurements were carried out twice with new sampling at $120{ }^{\circ} \mathrm{C}$.

The contact angle of water and diiodomethane were recorded and analysed at room temperature using a DSA 30E drop shape analysis system (Krüss, Germany). Smooth and horizontal sessile drops of the liquids (water, diiodomethane) were deposited on a solid surface (the PHU coatings). Needles of 0.5 $\mathrm{mm}$ diameter were used for both liquids. The contact angle was measured on static drops. Drop shape analysis was performed using Tangent method 1 . The reported contact angle values for water and diiodomethane are the mean of six drops deposited on two separate coating samples. The values of contact angles were measured $5 \mathrm{~s}$ after deposition. The contact angle deviation was less than $\pm 1.5^{\circ}$.

Mechanical tensile testing of the adhesive properties of obtained PHUs was performed using Instron, model 5566 (Instron Co., Canton, MA). Specimens were gripped by two screw-type flatplate grips and pulled at a strain speed of $10 \mathrm{~mm} \mathrm{~min}^{-1}$ with a load of $10 \mathrm{kN}$. The results are an average of the measurements performed on three samples.

\subsection{General procedure for the preparation of non-isocyanate poly(hydroxyurethane)s (PHUs)}

PHUs were synthesized by the reaction of five-membered bis(cyclic carbonate) with 1,3-diaminopropane and differing amounts of dimethyl succinate.

In the first step, the reaction of dimethyl succinate with 1,3diaminopropane was carried out. The 1,3-diaminopropane was placed in $250 \mathrm{~mL}$ round-bottomed flask equipped with mechanical stirrer and argon inlet. Then, the dimethyl succinate was added drop-wise at a rate of $5 \mathrm{~mL} \mathrm{~h}^{-1}$ using a dosing pump. The mixture was stirred at $45{ }^{\circ} \mathrm{C}$ until the carbonyl bond absorption band at $1760 \mathrm{~cm}^{-1}$ disappeared.

In the second step, bis(cyclic carbonate) was placed in a 100 $\mathrm{mL}$ round-bottomed flask equipped with a mechanical stirrer and a nitrogen inlet. The solid was melted at $80{ }^{\circ} \mathrm{C}$ under 
Table 1 PHU material formulation

\begin{tabular}{lllll}
\hline PHU & $\begin{array}{l}\text { Diglycerol } \\
\text { carbonate }(\mathrm{mol})\end{array}$ & $\begin{array}{l}\text { Diamine } \\
(\mathrm{mol})\end{array}$ & $\begin{array}{l}\text { Dimethyl } \\
\text { succinate }(\mathrm{mol})\end{array}$ & $\begin{array}{l}\text { Additive } \\
\left(\%_{\mathrm{mol}}\right)\end{array}$ \\
\hline MK & 0.047 & 0.056 & - & 0 \\
$0.8-\mathrm{MK}$ & 0.100 & 0.106 & 0.002 & 0.8 \\
1.8-MK & 0.092 & 0.099 & 0.003 & 1.8 \\
$2.7-\mathrm{MK}$ & 0.092 & 0.100 & 0.005 & 2.7 \\
$3.0-\mathrm{MK}$ & 0.066 & 0.065 & 0.004 & 3.0 \\
$3.6-\mathrm{MK}$ & 0.070 & 0.076 & 0.005 & 3.6
\end{tabular}

a nitrogen atmosphere. Then a mixture of 1,3-diaminopropane and dimethyl succinate was added. Because of the rapidly increasing viscosity of the reaction mixture preventing effective mixing, the temperature of the mixture was increased gradually to $150{ }^{\circ} \mathrm{C}$. The reaction was controlled by FT-IR spectroscopy. A by-product of the reaction was methanol, which was evaporated off. The obtained PHUs were analysed without further purification. The yields of reactions were quantitative.

The quantities of reagents together are shown in Table 1.

2.3.1 MK. Yield 98.4\%; ${ }^{1} \mathrm{H}$ NMR (DMSO-d $6,400 \mathrm{MHz}$ ); $\delta(\mathrm{ppm})=7.12\left(\mathrm{bs}, 1.82 \mathrm{H}, \mathrm{NH}_{(\mathrm{E})}\right), 6.76\left(\mathrm{bs}, 0.18 \mathrm{H}, \mathrm{NH}_{(\mathrm{z})}\right), 5.08$ (bs, 1.4H, OH), 4.89 (bs, 0.6H, OH), 4.68 (bs, 0.8H, CHO(CO)N), 3.98-3.78 (m, 2.5H, $\left.\mathrm{CH}_{2} \mathrm{OCH}_{2}\right), 3.78-3.66(\mathrm{~m}, 1.4 \mathrm{H}, \mathrm{CHOH})$, 3.56-3.21 (m, 5.3H, $\mathrm{CH}_{2} \mathrm{O}$ ), 3.00 (bs, $4 \mathrm{H}, \mathrm{CH}_{2} \mathrm{NH}$ ), 1.45 (bs, $2 \mathrm{H}$, $\mathrm{CH}_{2}$ ); ${ }^{13} \mathrm{C}$ NMR (DMSO-d ${ }_{6}, 100 \mathrm{MHz}$ ); 156.56, 156.23, 73.39, 72.76, 72.66, 70.60, 70.07, 67.93, 65.70, 60.97, 38.10, 29.66 FT-IR (ATR): $\nu\left(\mathrm{cm}^{-1}\right)=3307,2935,1687,1532,1441,1248,1039,773$, 565.

2.3.2 0.8-MK. Yield 99.0\%; ${ }^{1} \mathrm{H}$ NMR (DMSO-d 6 , $400 \mathrm{MHz}$ ); $\delta(\mathrm{ppm})=7.11\left(\mathrm{bs}, 1.60 \mathrm{H}, \mathrm{NH}_{(\mathrm{E})}\right), 6.74\left(\mathrm{bs}, 0.18 \mathrm{H}, \mathrm{NH}^{1}\right), 4.95$ (bs, 0.9H, OH), 4.89 (bs, 0.60H, OH), 4.66 (bs, 0.79H, CHO(CO) $\mathrm{N}), 3.98-3.78\left(\mathrm{~m}, 2.42 \mathrm{H}, \mathrm{CH}_{2} \mathrm{OCH}_{2}\right), 3.78-3.66(\mathrm{~m}, 1.30 \mathrm{H}$, $\mathrm{CHOH}), 3.56-3.21\left(\mathrm{~m}, 9.81 \mathrm{H}, \mathrm{CH}_{2} \mathrm{O}\right), 3.00$ (bs, $\left.4.00 \mathrm{H}, \mathrm{CH}_{2} \mathrm{NH}\right)$, 2.27 (bs, 0.10H, $\mathrm{CH}_{2} \mathrm{CH}_{2}$ ), 1.45 (bs, $2.0 \mathrm{H}, \mathrm{CH}_{2}$ ); ${ }^{13} \mathrm{C} \mathrm{NMR}$ (DMSO-d $6100 \mathrm{MHz}$ ); 171.80 (amide), 156.30, 155.99, 73.18, $72.66,72.55,70.52,69.90,67.79,65.54,60.12,37.97,33.25$ (amide) 29.83 FT-IR (ATR): $\nu\left(\mathrm{cm}^{-1}\right)=3312,2947,1685,1529$, 1443, 1245, 1038, 773, 562.

2.3.3 1.8-MK. Yield 98.7\%; ${ }^{1} \mathrm{H}$ NMR (DMSO-d 6 , $\left.400 \mathrm{MHz}\right)$; $\delta(\mathrm{ppm})=7.11\left(\mathrm{bs}, 1.62 \mathrm{H}, \mathrm{NH}_{(\mathrm{E})}\right), 6.75\left(\mathrm{bs}, 0.18 \mathrm{H}, \mathrm{NH}_{(\mathrm{Z})}\right), 4.95$ (bs, $1.00 \mathrm{H}, \mathrm{OH}), 4.89$ (bs, $0.50 \mathrm{H}, \mathrm{OH}), 4.66$ (bs, 0.60H, $\mathrm{CHO}(\mathrm{CO})$ $\mathrm{N}), 3.98-3.78\left(\mathrm{~m}, 2.50 \mathrm{H}, \mathrm{CH}_{2} \mathrm{OCH}_{2}\right), 3.78-3.66(\mathrm{~m}, 1.30 \mathrm{H}$, $\mathrm{CHOH}), 3.56-3.21\left(\mathrm{~m}, 9.70 \mathrm{H}, \mathrm{CH}_{2} \mathrm{O}\right), 3.00$ (bs, $4.00 \mathrm{H}, \mathrm{CH}_{2} \mathrm{NH}$ ), 2.27 (bs, 0.16H, $\mathrm{CH}_{2} \mathrm{CH}_{2}$ ), 1.48 (bs, $2.00 \mathrm{H}, \mathrm{CH}_{2}$ ); ${ }^{13} \mathrm{C} \mathrm{NMR}$ (DMSO-d $6100 \mathrm{MHz}$ ); 171.78 (amide), 156.57, 156.23, 73.40, $72.78,72.67,70.70,70.09,68.00,65.72,60.34,38.13,33.29$ (amide), 29.99 FT-IR (ATR): $\nu\left(\mathrm{cm}^{-1}\right)=3312,2938,1685,1529$, 1442, 1246, 1038, 773, 565.

2.3.4 2.7-MK. Yield 98.5\%; ${ }^{1} \mathrm{H}$ NMR (DMSO-d ${ }_{6}, 400 \mathrm{MHz}$ ); $\delta(\mathrm{ppm})=7.10\left(\mathrm{bs}, 1.60 \mathrm{H}, \mathrm{NH}_{(\mathrm{E})}\right), 6.75\left(\mathrm{bs}, 0.17 \mathrm{H}, \mathrm{NH}_{(\mathrm{z})}\right), 4.95$ (bs, $1.10 \mathrm{H}, \mathrm{OH}), 4.89$ (bs, $0.40 \mathrm{H}, \mathrm{OH}), 4.66$ (bs, $0.64 \mathrm{H}, \mathrm{CHO}(\mathrm{CO})$ $\mathrm{N}), 3.98-3.78\left(\mathrm{~m}, 2.46 \mathrm{H}, \mathrm{CH}_{2} \mathrm{OCH}_{2}\right), 3.78-3.66(\mathrm{~m}, 1.33 \mathrm{H}$, $\mathrm{CHOH}), 3.56-3.21\left(\mathrm{~m}, 9.96 \mathrm{H}, \mathrm{CH}_{2} \mathrm{O}\right), 3.00$ (bs, $\left.4.00 \mathrm{H}, \mathrm{CH}_{2} \mathrm{NH}\right)$, 2.27 (bs, $0.21 \mathrm{H}, \mathrm{CH}_{2} \mathrm{CH}_{2}$ ), 1.50 (bs, $2.00 \mathrm{H}, \mathrm{CH}_{2}$ ); ${ }^{13} \mathrm{C} \mathrm{NMR}$ (DMSO-d $6100 \mathrm{MHz}$ ); 171.68 (amide), 156.53, 156.19, 73.37,
72.76, 72.66, 70.67, 70.06, 67.97, 65.73, 60.32, 38.10, 33.20 (amide), 29.97 FT-IR (ATR): $\nu\left(\mathrm{cm}^{-1}\right)=3310,2917,2873,1686$, 1530, 1440, 1246, 1038, 773, 561.

2.3.5 3.0-MK. Yield 99.0\%; ${ }^{1} \mathrm{H}$ NMR (DMSO-d ${ }_{6}, 400 \mathrm{MHz}$ ); $\delta(\mathrm{ppm})=7.10\left(\mathrm{bs}, 1.61 \mathrm{H}, \mathrm{NH}_{(\mathrm{E})}\right), 6.76\left(\mathrm{bs}, 0.18 \mathrm{H}, \mathrm{NH}_{(\mathrm{z})}\right), 4.97$ (bs, $\left.1.39 \mathrm{H}, \mathrm{OH}_{\text {primary }}+\mathrm{OH}_{\text {secondary }}\right), 4.66$ (bs, $0.67 \mathrm{H}, \mathrm{CHO}(\mathrm{CO})$ $\mathrm{N}), 3.98-3.78\left(\mathrm{~m}, 2.76 \mathrm{H}, \mathrm{CH}_{2} \mathrm{OCH}_{2}\right), 3.78-3.66(\mathrm{~m}, 1.55 \mathrm{H}$, $\mathrm{CHOH}), 3.56-3.21\left(\mathrm{~m}, 9.48 \mathrm{H}, \mathrm{CH}_{2} \mathrm{O}\right), 3.00$ (bs, $\left.4.00 \mathrm{H}, \mathrm{CH}_{2} \mathrm{NH}\right)$, 2.27 (bs, $0.21 \mathrm{H}, \mathrm{CH}_{2} \mathrm{CH}_{2}$ ), 1.50 (bs, $2.05 \mathrm{H}, \mathrm{CH}_{2}$ ); ${ }^{13} \mathrm{C} \mathrm{NMR}$ (DMSO-d $6100 \mathrm{MHz}$ ); 171.67 (amide), 156.52, 156.18, 73.36, $72.75,72.65,70.66,70.05,67.93,65.72,60.28,38.08,33.20$ (amide), 29.95 FT-IR (ATR): $\nu\left(\mathrm{cm}^{-1}\right)=3308,2917,2874,2849$, 1686, 1537, 1440, 1247, 1038, 773, 565.

2.3.6 3.6-MK. Yield 98.0\%; ${ }^{1} \mathrm{H}$ NMR (DMSO-d 6 , $400 \mathrm{MHz}$ ); $\delta(\mathrm{ppm})=7.10\left(\mathrm{bs}, 1.35 \mathrm{H}, \mathrm{NH}_{(\mathrm{E})}\right), 6.76\left(\mathrm{bs}, 0.16 \mathrm{H}, \mathrm{NH}_{(\mathrm{Z})}\right), 4.97$ (bs, $\left.1.22 \mathrm{H}, \mathrm{OH}_{\text {primary }}+\mathrm{OH}_{\text {secondary }}\right), 4.66$ (bs, $0.60 \mathrm{H}, \mathrm{CHO}(\mathrm{CO})$ $\mathrm{N}), 3.98-3.78\left(\mathrm{~m}, 1.96 \mathrm{H}, \mathrm{CH}_{2} \mathrm{OCH}_{2}\right), 3.78-3.66(\mathrm{~m}, 1.11 \mathrm{H}$, $\mathrm{CHOH}), 3.56-3.21$ (m, 7.76H, $\mathrm{CH}_{2} \mathrm{O}$ ), 3.00 (bs, $4.00 \mathrm{H}, \mathrm{CH}_{2} \mathrm{NH}$ ), 2.27 (bs, $0.42 \mathrm{H}, \mathrm{CH}_{2} \mathrm{CH}_{2}$ ), 1.50 (bs, $2.03 \mathrm{H}, \mathrm{CH}_{2}$ ); ${ }^{13} \mathrm{C} \mathrm{NMR}$ (DMSO-d $6100 \mathrm{MHz}$ ); 171.60 (amide), 156.48, 156.14, 73.32, $72.73,72.63,70.63,70.02,67.89,65.69,60.63,38.05,33.18$ (amide) 29.92, FT-IR (ATR): $\nu\left(\mathrm{cm}^{-1}\right)=3309,2917,2847,2849$, 1687, 1538, 1440, 1247, 1038, 773, 562.

\subsection{Sample preparation}

Coatings were prepared using a K Paint Applicator equipped with a 4-Sided Applicator at an elevated temperature $\left(120^{\circ} \mathrm{C}\right)$. The coatings were prepared on clean, glass substrates $(25.4 \times$ $76.2 \mathrm{~mm}$ ). A coating was prepared using a gap width of $60 \mu \mathrm{m}$ and the wet film thickness provided was equal to half of the gap size.

The adhesive was applied to the surfaces of wood according to European Standard EN 311:2002. Two pieces of wood (birch wood, Betula L.) were coated with the obtained PHU melted at a temperature of $130{ }^{\circ} \mathrm{C}$. The two pieces of wood were subjected to hot pressing at $1.18 \mathrm{MPa}$ for $30 \mathrm{~min}$. The specimens were then cooled to solidify the adhesive. The bonding area of all samples measured $18 \times 25 \mathrm{~mm}$.

All coatings and adhesives were kept under an inert gas atmosphere prior to contact angle and mechanical measurements.

\section{Results and discussion}

The synthesis of diglycerol carbonate (bis(2,3-dihydroxypropyl) ether dicarbonate) from a commercially available diglycerol was shown previously. ${ }^{25}$ In this work, diglycerol carbonate is used to obtain new PHUs based on 1,3-diaminopropane and dimethyl succinate. These new PHUs have potential applications as adhesives or coatings. The incorporation of amide bonding (by using dimethyl succinate) to the PHU macromolecule may have an effect on the PHU's polarity, mechanical properties and viscosity.

\subsection{PHU characterization}

Diglycerol carbonate was used as a monomer in the synthesis of PHUs via a polyaddition reaction with 1,3-diaminopropane and 
using differing molar ratios of dimethyl succinate. The molar ratio of dimethyl succinate was in the $0.8-3.6 \%$ range. Polyaddition reactions were carried out using a solvent-free, catalyst-free method, resulting in various PUs with different backbones. Nevertheless, methanol was formed as a by-product. In the first step, compounds of diaminopropane and dimethyl succinate were prepared and then introduced to the dissolved diglycerol carbonate. The obtained PHUs were characterized by an additional amide bond. PHUs modified with esters have potential applications in environmentally friendly water-based, VOC-free coatings and adhesives. The reaction was monitored by FT-IR spectroscopy. During the reaction the strongest peak at $1785 \mathrm{~cm}^{-1}$ (assigned to the cyclic group) disappeared and new peaks appeared that are typical of hydroxyurethane (at 3312, 1687 and $1538 \mathrm{~cm}^{-1}$ ) and $\mathrm{N}-\mathrm{H}$ deformation of urethane groups $\left(1538 \mathrm{~cm}^{-1}\right)$. Characteristic absorption peaks for an $\mathrm{N}-\mathrm{H}$ stretch

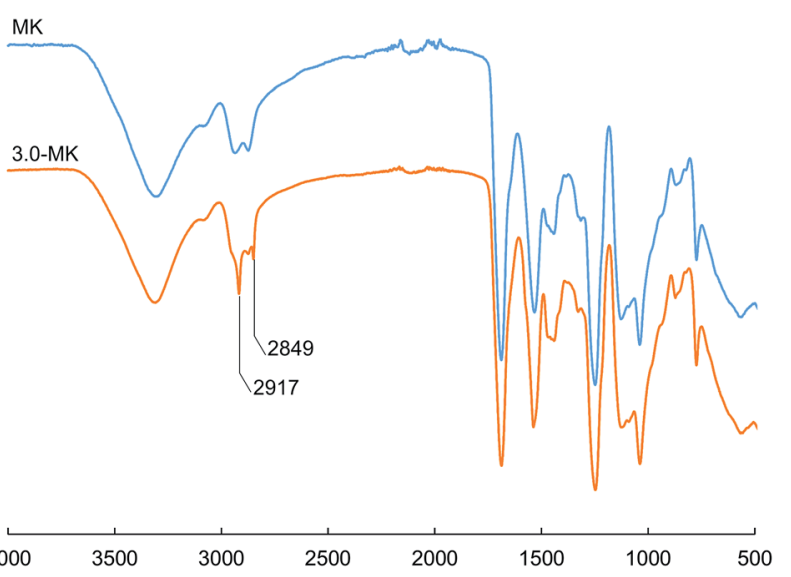

Fig. 1 FT-IR spectra of PHUs with and without amide backbone. and bending vibration for amide groups at $1550 \mathrm{~cm}^{-1}$ and 3200 $\mathrm{cm}^{-1}$ are overlapped by the absorption bands typical of hydroxyl or hydroxyurethane groups. From the analysis of the FT-IR spectrum of an amide adduct of dimethyl succinate and diamine and MK-PHU, characteristic bands for the $0.8-\mathrm{MK}$ to 3.6-MK PHUs appear at $2849 \mathrm{~cm}^{-1}$ and $2917 \mathrm{~cm}^{-1}$ (Fig. 1). These peaks can be assigned to $\mathrm{C}-\mathrm{H}$ stretch deformation in the methylene groups between carbonyl groups in the amide group. Fig. 1S (ESI $\dagger$ ) shows the comparison of FT-IR spectra of all PHUs.

The chemical structures of obtained PHUs were confirmed using ${ }^{1} \mathrm{H}$ NMR and ${ }^{13} \mathrm{C}$ NMR. We presented a detailed description of ${ }^{1} \mathrm{H}$ NMR and ${ }^{13} \mathrm{C}$ NMR spectra of PHUs based on diglycerol carbonate and aliphatic amines. ${ }^{25}$ Fig. 2 shows the repeating units region of the ${ }^{1} \mathrm{H}$ NMR spectrum typical of all of the synthesized PHUs. The signal of the urethane group $\mathrm{N}-\mathrm{H}$ was observed as two singlets at 7.11 and $6.64 \mathrm{ppm}$ due to the hindered rotation of the (CO)-N bond..$^{25}$ Furthermore, the free hydroxyl groups appear in the range 4.89-4.95 ppm as two broad separate signals for secondary and primary $\mathrm{OH}$ groups. On the other hand, for 3.0-MK and 3.6-MK the $\mathrm{OH}$ protons appear as single broad peaks. The intensity of the methylene protons $\left(\mathrm{CH}_{2}^{-}\right.$ $\mathrm{CH}_{2}$ ) in the succinate group increases with an increasing amount of additive (see Fig. 2S, ESI $\dagger$ ). The other diglycerol unit peaks appear as a multiplet in the range 3.21-3.98. The typical ${ }^{13} \mathrm{C}$ NMR of obtained PHU is shown on Fig. 3S (ESI $\dagger$ ).

The molecular weight and molecular weight distributions were not determined by GPC because of the lack of solubility of the polymers in typical solvents.

\subsection{Thermal characterization}

The thermal stabilities of PHUs were determined by TGA and DSC. The results are summarized in Table 2. The thermal

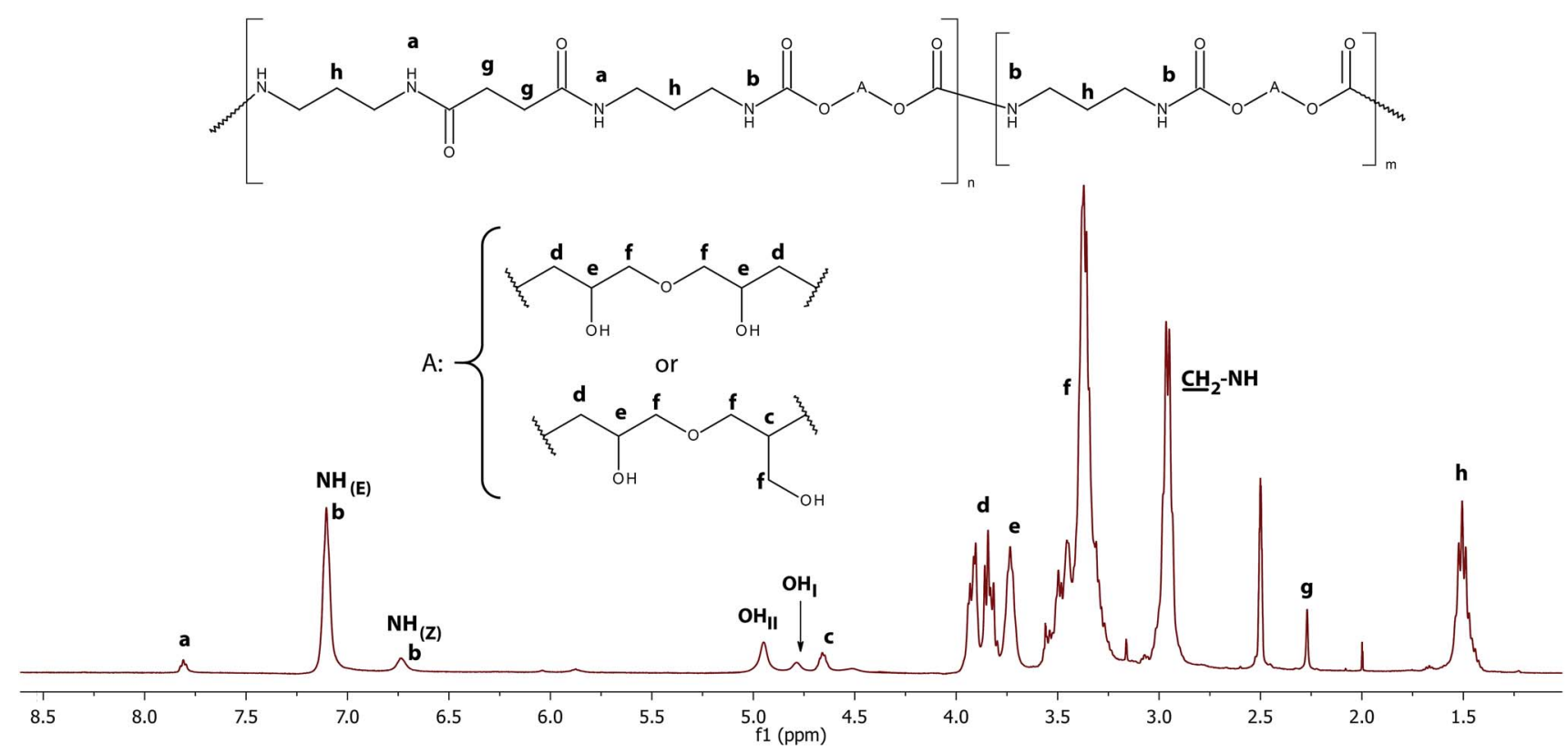

Fig. 2 The ${ }^{1} \mathrm{H}$ NMR (DMSO- $d_{6}, 400 \mathrm{MHz}$ ) spectrum of the 2.7-MK polymer. 
Table 2 Thermal properties and viscosity of the obtained PHUs

\begin{tabular}{lllll}
\hline PHU & $T_{\mathrm{g}}\left({ }^{\circ} \mathrm{C}\right)$ & $T_{\mathrm{d}, 5 \%}\left({ }^{\circ} \mathrm{C}\right)$ & $T_{\mathrm{d} \max }\left({ }^{\circ} \mathrm{C}\right)$ & $\eta($ Pa s $)$ \\
\hline MK & 18.8 & 197 & 258 & 11.3 \\
$0.8-\mathrm{MK}$ & 28.9 & 219 & 244 & 72.2 \\
1.8-MK & 26.4 & 221 & 243 & 87.3 \\
$2.7-\mathrm{MK}$ & 27.2 & 214 & 248 & 83.0 \\
3.0-MK & 26.1 & 192 & 238 & 70.0 \\
3.6-MK & 26.4 & 191 & 251 & 32.9
\end{tabular}

stabilities of the obtained PHUs are similar to those of other PHU materials reported in the literature. ${ }^{7,21,25-27}$ The obtained PHUs exhibited initial degradation ${ }^{4}$ between 191 and $221{ }^{\circ} \mathrm{C}$ and maximum decomposition rates between 238 and $258{ }^{\circ} \mathrm{C}$. The initial degradation temperature is higher for $1.8-\mathrm{MK}$ and 2.7-MK than for pure MK PHU. However, the maximum decomposition temperature is much lower for these PHUs than for MK PHU without an amide backbone. The values of $T_{\mathrm{g}}$ are higher for the PHUs with a amide backbone than for MK PHU.

\subsection{Viscosity}

The viscosities of the obtained PHUs are presented in Table 2. The addition of dimethyl succinate increases the viscosity of PHUs based on diglycerol carbonate and 1,3-aminopropane. The increase in viscosity with the addition of dimethyl succinate is not linear. The lowest viscosity was observed for MK PHU. The maximum value is observed for the PHU 1.8-MK and then the viscosity decreases for 2.7-MK, 3.0-MK and 3.6-MK PHUs.

\subsection{Surface free energy and work of adhesion}

To obtain the surface free energy of all samples and their adhesion parameters, contact angle measurements of two liquids were taken on the samples. The SFEs of investigated PHU coatings were calculated according to the Owens-Wendt method using water and diiodomethane. The Owens-Wendt method is described elsewhere. ${ }^{20,28}$ The surface tension of the tested liquids are presented in Table 3. The thermodynamic work of adhesion $W_{a}$ between two phases was calculated according to eqn (1). ${ }^{28}$

$$
W_{12}=\gamma_{1}+\gamma_{2}-\gamma_{12}
$$

$\gamma_{1}$ and $\gamma_{2}$ refer to the SFE of each solid (the PHU coating and the wood respectively), and $\gamma_{12}$ denotes the SFE of the interphase. The $\gamma_{12}$ was calculated using the Owens-Wendt model according to eqn (2). ${ }^{28}$

$$
\gamma_{12}=\gamma_{1}+\gamma_{2}-2 \sqrt{\gamma_{1}^{\mathrm{D}} \gamma_{2}^{\mathrm{D}}}-2 \sqrt{\gamma_{1}^{\mathrm{P}} \gamma_{2}^{\mathrm{P}}}
$$

The contact angle measurements, the determined values of interfacial free energy and work of adhesion are presented in Table 4.

The contact angles (see Table 4) show that the obtained PHU coatings have mostly hydrophilic surface properties, which
Table 3 Surface free energy data and the components of the test liquids used in this work ${ }^{a}$

\begin{tabular}{lcc}
\hline & Liquid & \\
\cline { 2 - 3 } Term & Water & Diiodomethane \\
\hline$\gamma^{\mathrm{T}}$ & 72.80 & 50.80 \\
$\gamma^{\mathrm{D}}$ & 21.80 & 48.50 \\
$\gamma^{\mathrm{P}}$ & 51.00 & 2.30 \\
${ }^{a} \gamma^{\mathrm{T}}-$ total surface tension, $\gamma^{\mathrm{D}}-$ dispersive component, $\gamma^{\mathrm{P}}-$ polar \\
component of surface tension.
\end{tabular}

Table 4 Values of contact angles, total surface free energy, its dispersion and polar component in $\mathrm{mN} \mathrm{m}^{-1}$ and values of work of adhesion

\begin{tabular}{llllllll}
\hline \multicolumn{9}{l}{$\begin{array}{l}\text { CA water } \\
\text { PHU }\end{array}$} & \multicolumn{2}{l}{$\begin{array}{l}\text { CA diiodomethane } \\
\left({ }^{\circ}\right)\end{array}$} & $\left.{ }^{\circ}\right)$ & $\gamma^{\mathrm{D}}$ & $\gamma^{\mathrm{P}}$ & $\gamma^{\mathrm{T}}$ & $\gamma_{12}$ & $W_{12}$ \\
\hline MK & 19.9 & 31.2 & 43.7 & 31.0 & 74.7 & 23.4 & 87.2 \\
0.8-MK & 24.3 & 25.7 & 45.9 & 28.2 & 74.1 & 21.2 & 88.7 \\
1.8-MK & 29.6 & 30.5 & 44.0 & 26.9 & 71.0 & 19.9 & 86.8 \\
2.7-MK & 25.7 & 31.1 & 43.7 & 28.8 & 72.5 & 21.5 & 86.9 \\
3.0-MK & 22.9 & 30.0 & 44.2 & 29.7 & 73.9 & 22.3 & 87.4 \\
3.6-MK & 24.0 & 29.9 & 44.3 & 29.2 & 73.5 & 21.9 & 87.4 \\
Wood & 113.1 & 48.3 & 35.2 & 0.6 & 35.8 & &
\end{tabular}

result from the presence of hydroxyl and urethane functional groups in the macromolecules of the PHUs. Moreover, lower values of the contact angle of water relate to a greater wettability of the coating. In previous work, we have shown that the PHU coatings absorb water. ${ }^{20}$ The SFE of obtained PHU coatings changes slightly with the addition of dimethyl succinate. The highest values of SFE are observed for the MK coating without the addition of dimethyl succinate. The lowest values of SFE are observed for the 1.8-MK coating.

Adhesion between liquid and solid surface is spontaneous only if the SFE of the substrate (solid phase) is greater than the surface tension of the liquid. The SFEs of 1.8-MK and MK PHUs are 70.97 and $74.72 \mathrm{~mJ} \mathrm{~m}^{-2}$ respectively. The SFE of wood (35.81 $\mathrm{mJ} \mathrm{m}^{-2}$ ) is lower than the SFEs of the PHUs, therefore, it can be expected that the adhesion between PHUs and wood would not be spontaneous.

Optimum adhesion can be achieved when the following conditions are fulfilled: maximum of work and adhesion $\left(W_{12}\right)$ minimum of SFE of interphase $\left(\gamma_{12}\right)$ and equality of SFE of both phases $\left(\gamma_{1}=\gamma_{2}\right)$. Considering only the work of adhesion parameter, it can be concluded that the best adhesion should be observed in the 0.8-MK-wood joint. The worst adhesion should be observed for the 1.8-MK-wood joint.

\subsection{Mechanical properties of adhesives}

In general, there is a lack of information on the adhesion properties of PHUs. However, the use of PU/PHU hybrid materials or PHU adhesives has been reported in the literature. ${ }^{21,22}$ The mechanical properties of PHU materials acting as a wood 
Table 5 Mechanical properties of PHUs

\begin{tabular}{llll}
\hline PHU & $\begin{array}{l}\text { Strain at break } \\
(\%)\end{array}$ & $\begin{array}{l}\text { Tensile } \\
\text { strength }\end{array}$ & $\begin{array}{l}\text { Young's } \\
\text { module }\end{array}$ \\
\hline MK & 9.7 & 0.12 & 1.26 \\
$0.8-\mathrm{MK}$ & 11.4 & 0.38 & 3.77 \\
1.8-MK & 14.4 & 0.67 & 5.42 \\
$2.7-\mathrm{MK}$ & 15.1 & 0.70 & 4.66 \\
$3.0-\mathrm{MK}$ & 12.5 & 0.41 & 3.36 \\
3.6-MK & 9.2 & 0.33 & 3.63
\end{tabular}

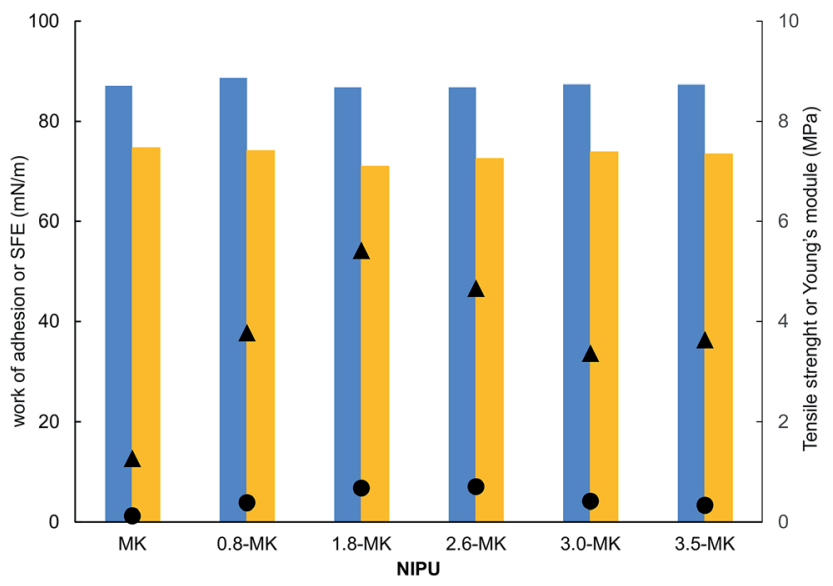

Fig. 3 Changes in surface free energy (yellow), work of adhesion (blue), tensile strength (O) and Young's module $(\boldsymbol{\Delta})$ of the obtained PHUs.

adhesive are summarized in Table 5. The highest values of tensile strength are for 1.8-MK (0.67 MPa) and 2.7-MK (0.70 $\mathrm{MPa})$. The lowest value of tensile strength is for MK (0.12 MPa) without any addition of dimethyl succinate. Better mechanical properties are directly related to higher initial decomposition temperatures and vice versa.

Fig. 3 compares SFE, adhesion parameters, tensile strength and Young's modulus. The adhesive joints showing the highest values of tensile strength and Young's modulus are characterized by lower values of adhesion parameters - for example 1.8MK. However, the values of $W_{12}$ are quite high. It might be concluded that in PHU-wood joints the cohesive forces of PHUs play the more significant role and not the adhesives forces between PHU and wood.

\section{Conclusions}

In this study, we carried out the synthesis of non-isocyanate poly(hydroxyurethane)s based on bis(cyclic carbonate) bis(2,3-dihydroxypropyl)ether and 1,3-diaminopropane - and various molar ratios of dimethyl succinate by an environmentally friendly route in a non-solvent process. Obtained PHUs were structurally characterized by FT-IR, ${ }^{1} \mathrm{H}$ NMR and ${ }^{13} \mathrm{C}$ NMR. Moreover, the materials were characterized by TGA and the viscosity of polymers was investigated.
The obtained PHUs were used as wood adhesives. The work of adhesion and the mechanical properties of PHU-wood joints were discussed. Dimethyl succinate increases the hydrophobicity of coatings by increasing the water contact angle and decreasing the polar component of the PHU coatings. Furthermore, the changes in hydrophilicity of PHU coatings are related to the changes in the mechanical properties of the adhesive joints. The obtained PHUs exhibited high thermal stability accompanied by good mechanical properties. Hence, PHU materials based on bis(cyclic carbonate), 1,3-diaminoprapone and dimethyl succinate are promising candidates as binders and in bonding applications.

\section{Acknowledgements}

This work was supported financially by the Faculty of Chemistry and Faculty of Production Engineering (Warsaw University of Technology, Poland).

\section{References}

1 L. Annunziata, A. K. Diallo, S. Fouquay, G. Michaud, F. Simon, J.-M. Brusson, J.-F. Carpentier and S. M. Guillaume, Green Chem., 2014, 16, 1947-1956.

2 C. Carre, L. Bonnet and L. Averous, RSC Adv., 2014, 4, 5401854025.

3 V. M. Lombardo, E. A. Dhulst, E. K. Leitsch, N. Wilmot, W. H. Heath, A. P. Gies, M. D. Miller, J. M. Torkelson and K. A. Scheidt, Eur. J. Org. Chem., 2015, 2015, 2791-2795.

4 L. Zhang, X. Luo, Y. Qin and Y. Li, RSC Adv., 2017, 7, 37-46. 5 K. M. F. Rossi de Aguiar, E. P. Ferreira-Neto, S. Blunk, J. F. Schneider, C. A. Picon, C. M. Lepienski, K. Rischka and U. P. Rodrigues-Filho, RSC Adv., 2016, 6, 19160-19172.

6 B. Nohra, L. Candy, J. F. Blanco, C. Guerin, Y. Raoul and Z. Mouloungui, Macromolecules, 2013, 46, 3771-3792.

7 J. L. J. van Velthoven, L. Gootjes, D. S. van Es, B. A. J. Noordover and J. Meuldijk, Eur. Polym. J., 2015, 70, 125-135.

8 L. Annunziata, A. K. Diallo, S. Fouquay, G. Michaud, F. Simon, J.-M. Brusson, J.-F. Carpentier and S. M. Guillaume, Green Chem., 2014, 16, 1947-1956.

9 M. Helou, J.-F. Carpentier and S. M. Guillaume, Green Chem., 2011, 13, 266-271.

10 A. Cornille, R. Auvergne, O. Figovsky, B. Boutevin and S. Caillol, Eur. Polym. J., 2017, 87, 535-552.

11 M. Fleischer, H. Blattmann and R. Muelhaupt, Green Chem., 2013, 15, 934-942.

12 S. Neffgen, J. Kusan, T. Fey, H. Keul and H. Hocker, Macromol. Chem. Phys., 2000, 201, 2108-2114.

13 G. Prompers, H. Keul and H. Hocker, Green Chem., 2006, 8, 467-478.

14 J. M. Raquez, M. Deleglise, M. F. Lacrampe and P. Krawczak, Prog. Polym. Sci., 2010, 35, 487-509.

15 C. Carre, L. Bonnet and L. Averous, RSC Adv., 2015, 5, 100390-100400.

16 L. Maisonneuve, O. Lamarzelle, E. Rix, E. Grau and H. Cramail, Chem. Rev., 2015, 115, 12407-12439. 
17 M. Blain, A. Cornille, B. Boutevin, R. Auvergne, D. Benazet, B. Andrioletti and S. Caillol, J. Appl. Polym. Sci., 2017, 134, 44958.

18 A. Cornille, M. Blain, R. Auvergne, B. Andrioletti, B. Boutevin and S. Caillol, Polym. Chem., 2017, 8, 592-604.

19 O. Figovsky, L. Shapovalov and F. Buslov, Surf. Coat. Int., Part $B, 2005,88,67-71$.

20 M. Tryznowski, J. Izdebska-Podsiadly and Z. ŻołekTryznowska, Progress in Organic Coitings, 2017, 109, 55-60.

21 A. Cornille, G. Michaud, F. Simon, S. Fouquay, R. Auvergne, B. Boutevin and S. Caillol, Eur. Polym. J., 2016, 84, 404-420.

22 E. K. Leitsch, W. H. Heath and J. M. Torkelson, Int. J. Adhes. Adhes., 2016, 64, 1-8.
23 K. Zhang, A. M. Nelson, S. J. Talley, M. Chen, E. Margaretta, A. G. Hudson, R. B. Moore and T. E. Long, Green Chem., 2016, 18, 4667-4681.

24 J. Nanclares, Z. S. Petrović, I. Javni, M. Ionescu and F. Jaramillo, J. Appl. Polym. Sci., 2015, 132, 42492.

25 M. Tryznowski, A. Swiderska, Z. Zolek-Tryznowska, T. Golofit and P. G. Parzuchowski, Polymer, 2015, 80, 228-236.

26 B. Ochiai and T. Utsuno, J. Polym. Sci., Part A: Polym. Chem., 2013, 51, 525-533.

27 V. Besse, G. Foyer, R. Auvergne, S. Caillol and B. Boutevin, J. Polym. Sci., Part A: Polym. Chem., 2013, 51, 3284-3296.

28 M. Zenkiewicz, Polimery, 2007, 52, 760-767. 